\title{
Effect of morphine and SIV on dendritic cell trafficking into the central nervous system of rhesus macaques
}

\author{
Rebecca Hollenbach ${ }^{1}$, Divya Sagar ${ }^{1}$, Zafar K. Khan ${ }^{1}$, Shannon Callen², Honghong Yao², \\ Jasmine Shirazi ${ }^{1}$, Shilpa Buch ${ }^{2, *}$, and Pooja Jain ${ }^{1, *}$ \\ ${ }^{1}$ Department of Microbiology and Immunology Drexel University College of Medicine, \\ Philadelphia, PA \\ ${ }^{2}$ Department of Pharmacology and Experimental Neuroscience University of Nebraska Medical \\ Center, Omaha, NE
}

\section{Abstract}

Recruitment of immune cells such as monocytes/macrophages and dendritic cells (DCs) across the blood-brain barrier (BBB) has been documented in diseases involving neuroinflammation. Neuroinvasion by HIV leads to neurocognitive diseases and alters the permeability of the BBB. Likewise, many HIV patients use drugs of abuse such as morphine, which can further compromise the BBB. While the role of monocytes and macrophages in neuroAIDS is well established, research demonstrating the presence and role of DCs in the CNS during HIV infection has not been developed yet. In this respect, this study explored the presence of DCs in the brain parenchyma of rhesus macaques infected with a neurovirulent form of SIV (SIV mac239 R71/17E) and administered with morphine. Cells positive for DC markers including CD11c (integrin), macDC-SIGN (dendritic cell-specific ICAM-3 grabbing nonintegrin), CD83 (a maturation factor) and HLA-DR (MHC class II) were consistently found in the brain parenchyma of SIV-infected macaques as well as infected macaques on morphine. Control animals did not exhibit any DC presence in their brains. These results provide first evidence of DCs' relevance in NeuroAIDS vis-à-vis drugs of abuse and open new avenues of understanding and investigative HIV-CNS inflictions.

\section{Keywords}

drugs of abuse; blood-brain barrier; dendritic cell trafficking; central nervous system; SIV infection; fluorescent immunohistochemistry

\section{Introduction}

Chronic HIV infection is frequently accompanied by different neuropathologies known collectively as HIV-associated neurocognitive disorders (HAND), which vary in severity and include HIV-associated dementia (HAD) and HIV encephalitis (HIVE) (Shapshak et al, 2011). The neurological effects of HIVE and HAD include neuroinflammation, lesions and cognitive decline. The prevalence of HAND is becoming a major concern given the aging population of individuals affected by HIV, who are already at risk for age-related

\footnotetext{
"Corresponding authors: Pooja Jain, Ph.D. Department of Microbiology \& Immunology, and the Drexel Institute of Biotechnology and Virology Research Drexel University College of Medicine 3805 Old Easton Road, Doylestown, PA 18902, USA Tel: 215-589-6441, Fax: 215-489-4920 pjain@ drexelmed.edu Laboratory webpage: www.pjainlab.com Shilpa Buch, Ph.D. Department of Pharmacology and Experimental Neuroscience University of Nebraska 985880 Nebraska Medical Center Omaha, NE 68198-5880, USA Tel: 402-559-3165 sbuch@unmc.edu.
} 
neurocognitive impairment and neurodegenerative diseases (Shapshak et al, 2011). Due to effective management of disease via highly active anti-retroviral therapy (HAART), the HIV-1 positive senior population in the Unites States rose over 6\% between 2001 and 2005 (Shapshak et al, 2011). Evidence of neuroinvasion by HIV can be obtained very early during infection, long before symptoms of neuroAIDS arise (Spudich et al, 2011). A pattern of drug abuse often coincides with individuals affected by HIV. Not only is HIV frequently transmitted via drug use, drug abusers infected with HIV are also more likely to be affected by HAND than infected non-users (Bokhari et al, 2011).

The blood-brain barrier (BBB) normally controls cellular infiltration into the CNS, but can be breached during neuroinflammatory disease. As a result of severe inflammation and infectivity of immune cells during HIVE, monocytes harboring the virus can cross the BBB, before differentiating into perivascular macrophages that act as viral reservoirs (Buckner et al, 2011; Orenstein et al, 1997). While the role of monocytes and macrophages in HIV infection during neuroAIDS is well characterized, a concise investigation of the presence and role of dendritic cells (DCs) in the CNS during HIV is lacking. DCs are effective antigen presenting cells of myeloid origin whose interaction with naïve $\mathrm{T}$ cells mediates an immune response (Ilarregui et al, 2009). In previous studies, we have shown real time trafficking of DCs in the inflamed spinal cord of animals afflicted with EAE (experimental autoimmune encephalomyelitis), a mouse model for MS (Jain et al, 2010; Sagar et al, 2012). Further, the role of CCL2 in the trafficking of DCs across the BBB has been established (Sagar et al, 2012). Encephalitis that ensues from HIV-associated neurocognitive disorders, like MS, has an inflammatory component that compromises BBB permeability. HIV infection can result in modification of the BBB through changes in tight junction proteins and chemokine regulation (Annunziata, 2003). In this respect, CCL2 or MCP-1 (monocyte chemoattractant protein-1), has been implicated in HIV encephalitis (Buckner et al, 2011; Conant et al, 1998; Dhillon et al, 2008; Eugenin et al, 2006; Johnson et al, 2004; Lee et al, 2011; Zink et al, 2001) and is known to attract monocytes, thus being a measure for clinical disease progression in infected macaques (Kumar et al, 2006). Morphine has also been shown to upregulate platelet derived growth factor, which leads to a reduction of the tight junction protein ZO-1 expression (Wen et al, 2011). There is a small body of accumulating evidence that morphine may protect the brain against the neurotoxicity during HIV infection, thereby managing to maintain a persistent, low viral load (Cloak et al, 2011). Also, long-term opiate dependence may in fact slow down viral progression (Donahoe et al, 2009) attributing the variability in disease progression found by different studies to other stress factors such as intense opiate administration/withdrawal regimen and the use of different viral strains. However, typically high plasma and cerebral spinal fluid (CSF) viral loads (Bokhari et al, 2011; Kumar et al, 2006) along with BBB breach typically characterize morphine administered virus infected macaques giving way to severe inflammation and encephalitis. Additionally, morphine administered rhesus macaque models of SIV have shown decreased antioxidant activity that can lead to oxidative tissue injury with more rapid disease progression (Perez-Casanova et al, 2008; Perez-Casanova et al, 2007) and increased levels of CCR5 receptors on peripheral blood mononuclear cells allowing a further increase in infectivity (Suzuki et al, 2002). In some monkeys administered with morphine, Tat sequence diversity correlated with slower progressing viremia (characterized by stable viral load and acquisition of opportunistic infections by 52 weeks post viral inoculation; (Noel and Kumar, 2006)) and diminished virus evolution in general across both rapid progressors (characterized by high viral load leading to death from severe encephalitis between 5-20 weeks post inoculation) and slow progressors (Tirado and Kumar, 2006).

The study presented herein is the first to demonstrate the penetration of DCs in the CNS in the brain parenchyma of rhesus macaques infected with SIV and administered with morphine. Future studies will provide a better understanding of the physiology behind the 
detrimental neuroinflammatory effects of neuroAIDS on the CNS can lead to the creation of more effective therapeutic drugs.

\section{Materials and Methods}

\section{Macaques}

Nine 2- to 3-year-old Indian rhesus macaques (Macaca mulatta) were purchased from the Caribbean Research Primate Center and individually housed in steel holding cages in two dedicated rooms within the AAALAC-approved animal facility at the University of Kansas Medical Center. The monkeys were exposed, daily, to $12 \mathrm{~h}$ light-dark cycles and given laboratory chow and water ad libitum along with daily snacks. All cages were equipped with environmental enrichments. The animals were tested for tuberculosis, herpes B virus, and simian retrovirus and found negative in all these tests. All animal protocols were approved by the Institutional Animal Care and Use Committee (IACUC) at the University of Kansas Medical Center. The animals were randomly divided into three groups: Control $(n=3)$, SIV only $(n=3)$ and SIV + morphine ( $n=3)$. Morphine was administered intramuscularly (IM) four times daily, at $6 \mathrm{~h}$ intervals, at a dose of $3 \mathrm{mg} / \mathrm{kg}$ with a $1 \mathrm{ml}$ syringe ( $27.5 \mathrm{G}$ needle). The SIV + morphine group macaques were gradually acclimated to morphine by starting with $1 \mathrm{mg} / \mathrm{kg}$ for 1 week and escalating to a final dose of $3 \mathrm{mg} / \mathrm{kg}$. The SIV group animals were injected with saline IM at the same time intervals. Morphine administration was maintained throughout the study to avoid withdrawal effects. For all animal studies, clinical grade morphine was purchased from the University of Kansas Medical Center Pharmacy.

\section{Infection}

SIVmacR71/17E (Raghavan et al, 1999) was originally prepared from pooled brain homogenates from macaques infected with R17 and R71E, both of which cause encephalitis. Virus stock was prepared in CD8+ T cell depleted, ConA-activated macaque peripheral blood mononuclear cells (PBMC) and assayed for infectivity in CEMx174 cells and by plaque assay in GHOST Hi5 cells. The animals were inoculated intravenously with approximately $10^{4}$ plaque-forming units of virus 9 weeks following initiation of morphine administration.

\section{Routine collection of samples}

Blood and CSF samples were collected at weekly intervals for the first month and monthly thereafter based on the previously published studies (Bokhari et al, 2011). The animals were anesthetized with ketamine and peripheral blood was collected in EDTA. Approximately 1 $\mathrm{ml}$ of CSF was collected from the cisterna magna. Levels of circulating $\mathrm{CD} 4^{+}$and $\mathrm{CD} 8^{+} \mathrm{T}$ cells as well as viral loads in plasma and CSF were monitored for over 8 months post-virus inoculation (PI).

\section{Necropsy}

All monkeys were monitored daily for evidence of disease (diarrhea, respiratory difficulties, progressive neurological signs, etc.) and alterations in attitude, appetite, or behaviors suggestive of illness (lack of movement, severely withdrawn behavior, lack of eating and/or drinking, etc.). Once these symptoms become unresponsive to treatment, the monkeys were euthanized. In preparation for necropsy, the animals were deeply anesthetized with ketamine $(3 \mathrm{mg} / \mathrm{kg})$ and medetomidine $(0.15 \mathrm{mg} / \mathrm{kg})$ given IM. Laparotomies were then performed, and the animals were exsanguinated from the descending aorta and perfused transcardially with normal saline. Samples of all the tissues including brain were harvested. Brains were dissected and portions of the parietal cortex, basal ganglia, frontal cortex, occipital cortex, and brainstem were collected. Adjacent portions of each tissue were frozen in liquid 
nitrogen-cooled isopentane and stored frozen at $-80^{\circ} \mathrm{C}$ for later determination of viral RNA content. Other portions were placed into cassettes and fixed in 4\% paraformaldehyde or $10 \%$ formalin. These cassettes were then processed for routine histopathological analysis.

\section{Antibodies}

Mouse-anti-human-CD11c-Alexa Fluor 647 (Biolegend, San Diego, CA), mouse-antihuman-CD31-FITC (BD Pharmingen, San Jose, CA) and mouse-anti-human-CD83-PE (Biolegend), mouse-anti-human-HLA-DR-FITC (Biolegend) and mouse-anti-macaque-DCSIGN-PE (Santa Cruz Biotechnology, Santa Cruz, CA) fluorophore-conjugated primary antibodies were used for fluorescent immunohistochemistry analyses. The following reagent was obtained through the AIDS Research and Reference Reagent Program: SIVmac p27 Monoclonal Antibody (55-2F12) from Dr Niels Pedersen (Higgins et al, 1992). Goat-antimouse-Alexa Fluor 350 (Invitrogen, Carlsbad, CA) was used for secondary detection of SIV p27.

\section{Fluorescent Immunohistochemistry}

Frozen frontal cortex coronal sections on glass slides were baked overnight at $55^{\circ} \mathrm{C}$ to firmly affix and dehydrate the tissue. Paraffin-embedded monkey brain tissue sections were deparaffinized in xylene and rehydrated in a graded series of alcohol. Briefly, slides were immersed twice in $100 \%$ xylene for $3 \mathrm{~min}$, followed by a $3 \mathrm{~min}$ wash with a 1:1 solution of xylene and $100 \%$ ethanol. Slides were then washed in 100, 95, 70 and 50\% ethanol followed by a cold water bath, each for $3 \mathrm{~min}$. Thereafter, slides were boiled in $10 \mathrm{mM}$ sodium citrate pH 6.0 for $20 \mathrm{~min}$, followed by two 5 min washes with Tris buffered saline (TBS) $+0.025 \%$ Triton X-100, then permeabilized for $30 \mathrm{~min}$ in $0.1 \%$ triton X-100 in TBS. Slides were blocked in $10 \%$ mouse serum with $1 \%$ BSA in TBS for $2 \mathrm{~h}$ at room temperature. After blocking, the slides were stained with fluorophore conjugated primary antibodies at a concentration of 1:100 overnight at $4^{\circ} \mathrm{C}$. Two-step staining protocols were carried out in the case of SIV p27 detection, in which slides were probed for $\mathrm{p} 27$ at a concentration of 1:100 overnight at $4{ }^{\circ} \mathrm{C}$, followed by detection with goat-anti-mouse-Alexa Fluor 350 at a concentration of 1:5000 for $1 \mathrm{~h}$ at room temperature. Slides were then probed with remaining antibodies as described above. Slides were washed thrice in TBS $+0.025 \%$ Triton $\mathrm{X}-100$. Where indicated, slides were counter-stained with $1 \mathrm{ug} / \mathrm{ml}$ DAPI. Following staining, slides were dried and a series of 40x and 100x Z-stack images were collected using the Olympus IX81 inverted microscope and analyzed using 3I Slidebook software.

\section{Results}

We examined the presence of DCs in the CNS of SIV-infected rhesus macaques, a common model organism for human HIV infection. Three study groups were established: noninfected control animals, macaques infected with SIV, and macaques infected with SIV and administered chronic morphine. Macaques were infected with a particularly neurovirulent SIV strain derived from SIVmac239 known as R71/17E, which closely mimics HIV pathogenesis by infecting $\mathrm{CD}^{+}{ }^{+} \mathrm{T}$ cells (Bokhari et al, 2011; Raghavan et al, 1999). Animals were monitored for behavioral changes, and blood and CSF samples were routinely taken and measured for viral RNA content as number of Gag copies per ml to monitor disease (Figure 1A). Viral RNA in blood and CSF were detectable within 1 week post inoculation and remained higher in the SIV + morphine group up until week 20. Thereafter, viral burden was comparable between SIV and SIV + morphine groups until week 51. Since the frontal cortices of macaque brains were utilized in the subsequent immunohistochemical staining, viral titers from these regions were also measured (as number of Gag copies per million GAPDH copies) to estimate tissue viral load upon autopsy at week 51. Viral load in 
frontal cortex showed higher but non-significant $(\mathrm{p}=0.5)$ increase in the SIV + morphine group as compared with the SIV only group (Figure 1B).

To confirm the presence of DCs in the brain parenchyma of infected animals, we probed coronal frontal cortex sections with CD11c (red) to detect DCs and CD31 (green) to demarcate vasculature. While in the control group immune cells remained within the vasculature, SIV-infected macaques with and without morphine both showed penetration of CD $11 \mathrm{c}^{+}$cells into the surrounding perivascular regions, as highlighted by the white arrow in the middle panel (Figure 1C). Additionally, we consistently observed enhanced vasodilation in the morphine treated group, a likely artifact of the compromised BBB (Wen et al, 2011). In order to quantify these differences DAPI counterstaining was done to enumerate the total number of cells visualized, six random frames per study group were obtained and the frequency of CD $11 c^{+}$cells was determined in each experimental sample. Both SIV and SIV + morphine animals exhibited a higher frequency of CD11 $\mathrm{c}^{+}$cells, $3.9 \% \pm 0.2 \mathrm{SEM}$ (Standard Error of Mean) and 6.2\% \pm 1.8 , respectively, compared to the control group 1.0\% \pm 1.0 (Table 1$)$. While a small percentage of CD11 $\mathrm{c}^{+}$cells $(1.0 \%)$ was detected in the control group, they remained entirely within the microvasculature, as depicted in figure $1 \mathrm{C}$. We also performed the statistical analysis of the data to determine the $p$ value between the control un-infected group to the SIV-infected or SIV-infected plus morphine administered group. The comparison of DC numbers in Control versus SIV group was found to be significant ( $\mathrm{p} \unlhd .05$ ), while Control versus SIV + Morphine was close to being significant $(\mathrm{p}=0.07)$. SIV + Morphine group in general showed a higher frequency of CD11 $\mathrm{c}^{+}$cells but the difference did not reach to the significance $(\mathrm{p}=0.3)$.

As CD11c is a marker of cells of the myeloid lineage, including macrophages and monocytes, we next validated the presence of DCs distinctively by observing DC-specific cell surface markers. As shown in figure 2A, we observed macaque-specific DC-SIGN (macDC-SIGN, red) positive cells in the brain parenchyma of SIV-infected macaques and $\mathrm{SIV}+$ morphine macaques, but not in the control group. To further validate the presence of these cells at the site of SIV lesions, we stained for the mature SIV Gag protein, p27 (blue), as well as macDC-SIGN (red) and CD31 (green). Interestingly, compared to control animals we found sites of distinct perivascular cuffing in SIV-infected animals that clearly showed the accumulation of DCs around the microvasculature (Figure 2B, overlay). Perivascular cuffing, frequently seen in MS and EAE is the result of the accumulation of lymphocytes around the vasculature and is indicative of ongoing inflammation. In the SIV + morphine group, the phenomenon was more pronounced with DC infiltration into the surrounding tissue (Figure 2B, bottom panel). To further attest to the presence of DCs, markers representing maturation (CD83) and antigen presenting abilities (HLA-DR) were examined. While the control images showed a small degree of non-specific auto fluorescence, the SIVinfected groups showed distinct cells positive for both HLA-DR (green) and CD83 (red) as highlighted by the red circle in the middle panel (Figure $2 \mathrm{C}$ ), creating an even more convincing body of evidence demonstrating DC presence in the brain parenchyma.

\section{Discussion}

Dendritic cells are well known antigen-presenting cells that play a key role in the generation of a robust immune response. As classic immunological sentinels, they participate not only in antigen presentation, but chronic immune cell activation through dysregulation of proinflammatory chemokines and cytokines such as TLR7 and IFN-a (O'Brien et al, 2011; Sabado et al, 2010) and lymphocyte infection. Despite years of effective disease control with HAART, both patients infected with HIV and macaques infected with SIV exhibit high levels of viral DNA and low-level inflammation in the CNS demonstrating the critical need for a better understanding of the neuropathogenesis of HIV (Eden et al, 2007; Zink et al, 
2010). Heroin, which is converted to morphine in the brain, is often abused by HIV-infected persons and can further exacerbate disease. For example, chronic morphine exposure can upregulate CCR5 expression on neutrophils, monocytes and macrophages and may lead to increased infiltration of immune cells into the CNS (Bokhari et al, 2011). In addition, morphine, a known vasodilator, has been linked to increased permeability of the microvascular endothelial cells of the BBB (Potula et al, 2004; Wen et al, 2011).

While the role of monocytes and macrophages in HIV infection and neuroAIDS has been extensively explored, current knowledge of the presence and role of DCs during neuroAIDS is inadequate. For the first time here, we provide direct evidence that DCs are present in the CNS during SIV infection. Macaques in our study were slow progressors, with viral infection lasting over 8 months after which they were euthanized. We expect that a greater viral load should be an indicator of higher infiltration of immune cells into the brain. Our finding of a slightly higher proportion of DCs infiltrating into the brain of morphine treated virus infected macaques (Table 1) correlates with observed higher viral titer in these macaques (Figure 1A-B). We first demonstrated the presence of $\mathrm{CD} 11 \mathrm{c}^{+}$cells in the brain parenchyma of SIV-infected animals (Figure 1C) and quantification verified an increased frequency of these cells in the CNS of infected animals upon SIV infection (Table 1). Importantly, although we did not see a significant increase (due to small sample size and the fact that these macaques were slow progressors that only achieve mild to moderate encephalitis) in the number of transmigrated cells upon morphine exposure in infected animals, we did see increased vasodilation that reflects an enhanced neuropathology.

Since other myeloid-origin immune cells such as monocytes and macrophages also express $\mathrm{CD} 11 \mathrm{c}$, we extended our investigation to include more specific DC markers. For this, we assessed macDC-SIGN expression and clearly observed positive cells, which were lacking in the control animals (Figure 2A). Mac-DCSIGN is the macaque homolog of DC-SIGN in humans and has been characteristic of DC-specific studies in SIV infection (Changyong et al, 2010; de Witte et al, 2008; Xia et al, 2009; Yu Kimata et al, 2002). In general, DC-SIGN is considered a specific marker primarily for the tissue specific DCs (Soilleux et al, 2002), a subset of BDCA-2 ${ }^{+}$plasmacytoid DC precursors, and monocyte-derived DCs (MDDCs). It was shown to be further expressed on certain tissue macrophages such as in the alveoli and lung of developing fetus; however, its expression disappeared after development of the fetal alveoli (Soilleux et al, 2002). DCSIGN expression level was also measured at 65 fold higher in DCs versus monocytes (Geijtenbeek et al, 2000). Lastly, to confirm our findings, we analyzed the presence of DC markers associated with cellular maturity. $\mathrm{CD} 83^{+}$cells isolated from blood and shown to have the characteristic cellular morphology and functional activities of DCs (Pichyangkul et al, 2001; Zhou and Tedder, 1995). This population of $\mathrm{CD} 3^{+}$cells typically express the highest levels of MHC class II molecules, a hallmark of DCs, when compared with other leukocyte lineages. As detailed in Figure 2C, we observed $\mathrm{CD}^{+} 3^{+}$staining in SIV-infected animals, as well as $\mathrm{HLADR}^{+}$, which indicates the presence of MHC class II markers and the ability to carry out antigen presentation.

Recent work by others and us has established the trafficking of DCs into the CNS during other neuroinflammatory diseases such as EAE (Jain et al, 2010; Zozulya et al, 2009) and MS (Hatterer et al, 2008). DCs in the CNS could also be differentiated from the circulating myeloid precursors (Ifergan et al, 2008). Once in the CNS, DCs were found to act as potent APCs, activating $\mathrm{T}$ helper lymphocytes and allowing immune invasion and relapse in the CNS (Bailey et al, 2007; Greter et al, 2005). These studies are the first to decisively determine the presence of DCs in the CNS of subjects with SIV and open a new area of research in the field of HIV neuropathogenesis. DC interaction with other immune cells may perpetuate the neuroinflammatory symptoms of neuroAIDS by contributing to the cytokine dysregulation occurring in the CNS. Exposure to drugs of abuse further impacts the 
neuropathogenesis associated with AIDS, however the manner remains underexplored. The induced vulnerability of the CNS to infection only exacerbates the increase in neuronal apoptosis observed in the presence of both morphine and gp $120_{\text {IIIB }}$ due to greater $\mathrm{p} 38$ MAPK activation (Hu S, 2005). An important factor in the interaction between morphine and immune cells is the presence of the mu-opioid receptor, which is primarily targeted by morphine and is known to be present on DCs (Li Z, 2009). Morphine exposure causes lipopolysaccharide-matured DCs to display an increased T cell stimulatory capacity as well as increased IL-12 production through the p38 MAPK pathway (Messmer D, 2006). Given the known effects that morphine has on DCs, it is likely that these phenomena play a role in HIV pathogenesis. Further investigations would greatly advance the understanding of neuroAIDS by unraveling the mechanism of DC transmigration across the BBB and its function once present in the CNS. A better understanding of the role DCs and drugs of abuse play in neuroAIDS will lead to more effective drug therapies.

\section{Acknowledgments}

This work was funded by the Public Health Service, National Institutes of Health through the following grants: NIAID: AI077414 (PI: Pooja Jain) and AI093172-01 (PI: Zafar K. Khan). We also wish to thank the Philadelphia NeuroAIDS Training Grant: T32 MH079785, and the technical assistance provided by Ms. Anne Lamontagne.

\section{References}

Annunziata P. Blood-brain barrier changes during invasion of the central nervous system by HIV-1. Old and new insights into the mechanism. J Neurol. 2003; 250:901-6. [PubMed: 12928906]

Bailey SL, Schreiner B, McMahon EJ, Miller SD. CNS myeloid DCs presenting endogenous myelin peptides 'preferentially' polarize CD4+ T(H)-17 cells in relapsing EAE. Nat Immunol. 2007; 8:172-80. [PubMed: 17206145]

Bokhari SM, Hegde R, Callen S, Yao H, Adany I, Li Q, Li Z, Pinson D, Yeh HW, Cheney PD, Buch $\mathrm{S}$. Morphine potentiates neuropathogenesis of SIV infection in rhesus macaques. J Neuroimmune Pharmacol. 2011; 6:626-39. [PubMed: 21431470]

Buckner CM, Calderon TM, Willams DW, Belbin TJ, Berman JW. Characterization of monocyte maturation/differentiation that facilitates their transmigration across the blood-brain barrier and infection by HIV: implications for NeuroAIDS. Cell Immunol. 2011; 267:109-23. [PubMed: 21292246]

Changyong C, Sun M, Li H, Brockmeyer N, Wu NP. Simian virus 40 inhibits differentiation and maturation of rhesus macaque DC-SIGN(+) dendritic cells. Eur J Med Res. 2010; 15:377-82. [PubMed: 20952346]

Cloak CC, Chang L, O’Neil SP, Ernst TM, Anderson DC, Donahoe RM. Neurometabolite abnormalities in simian immunodeficiency virus-infected macaques with chronic morphine administration. J Neuroimmune Pharmacol. 2011; 6:371-80. [PubMed: 20938808]

Conant K, Garzino-Demo A, Nath A, McArthur JC, Halliday W, Power C, Gallo RC, Major EO. Induction of monocyte chemoattractant protein-1 in HIV-1 Tat-stimulated astrocytes and elevation in AIDS dementia. Proc Natl Acad Sci U S A. 1998; 95:3117-21. [PubMed: 9501225]

de Witte L, de Vries RD, van der Vlist M, Yuksel S, Litjens M, de Swart RL, Geijtenbeek TB. DCSIGN and CD150 have distinct roles in transmission of measles virus from dendritic cells to Tlymphocytes. PLoS Pathog. 2008; 4:e1000049. [PubMed: 18421379]

Dhillon NK, Williams R, Callen S, Zien C, Narayan O, Buch S. Roles of MCP-1 in development of HIV-dementia. Front Biosci. 2008; 13:3913-8. [PubMed: 18508485]

Donahoe RM, O'Neil SP, Marsteller FA, Novembre FJ, Anderson DC, Lankford-Turner P, McClure HH. Probable deceleration of progression of Simian AIDS affected by opiate dependency: studies with a rhesus macaque/SIVsmm9 model. J Acquir Immune Defic Syndr. 2009; 50:241-9. [PubMed: 19194320] 
Eden A, Price RW, Spudich S, Fuchs D, Hagberg L, Gisslen M. Immune activation of the central nervous system is still present after $>4$ years of effective highly active antiretroviral therapy. $\mathrm{J}$ Infect Dis. 2007; 196:1779-83. [PubMed: 18190258]

Eugenin EA, Osiecki K, Lopez L, Goldstein H, Calderon TM, Berman JW. CCL2/monocyte chemoattractant protein-1 mediates enhanced transmigration of human immunodeficiency virus (HIV)-infected leukocytes across the blood-brain barrier: a potential mechanism of HIV-CNS invasion and NeuroAIDS. J Neurosci. 2006; 26:1098-106. [PubMed: 16436595]

Geijtenbeek TB, Torensma R, van Vliet SJ, van Duijnhoven GC, Adema GJ, van Kooyk Y, Figdor CG. Identification of DC-SIGN, a novel dendritic cell-specific ICAM-3 receptor that supports primary immune responses. Cell. 2000; 100:575-85. [PubMed: 10721994]

Greter M, Heppner FL, Lemos MP, Odermatt BM, Goebels N, Laufer T, Noelle RJ, Becher B. Dendritic cells permit immune invasion of the CNS in an animal model of multiple sclerosis. Nat Med. 2005; 11:328-34. [PubMed: 15735653]

Hatterer E, Touret M, Belin MF, Honnorat J, Nataf S. Cerebrospinal fluid dendritic cells infiltrate the brain parenchyma and target the cervical lymph nodes under neuroinflammatory conditions. PLoS One. 2008; 3:e3321. [PubMed: 18830405]

Higgins JR, Sutjipto S, Marx PA, Pedersen NC. Shared antigenic epitopes of the major core proteins of human and simian immunodeficiency virus isolates. J Med Primatol. 1992; 21:265-9. [PubMed: 1383547]

Hu SSW, Lokensgard JR, Peterson PK. Morphine Potentiates HIV-1 gp120-Induced Neuronal Apoptosis. Journal of Infectious Diseases. 2005; 191:886-889. [PubMed: 15717263]

Ifergan I, Kebir H, Bernard M, Wosik K, Dodelet-Devillers A, Cayrol R, Arbour N, Prat A. The bloodbrain barrier induces differentiation of migrating monocytes into Th17-polarizing dendritic cells. Brain. 2008; 131:785-99. [PubMed: 18156156]

Ilarregui JM, Croci DO, Bianco GA, Toscano MA, Salatino M, Vermeulen ME, Geffner JR, Rabinovich GA. Tolerogenic signals delivered by dendritic cells to T cells through a galectin-1driven immunoregulatory circuit involving interleukin 27 and interleukin 10. Nat Immunol. 2009; 10:981-91. [PubMed: 19668220]

Jain P, Coisne C, Enzmann G, Rottapel R, Engelhardt B. Alpha4beta1 integrin mediates the recruitment of immature dendritic cells across the blood-brain barrier during experimental autoimmune encephalomyelitis. J Immunol. 2010; 184:7196-206. [PubMed: 20483748]

Johnson MD, Kim P, Tourtellotte W, Federspiel CF. Transforming growth factor beta and monocyte chemotactic protein-1 are elevated in cerebrospinal fluid of immunocompromised patients with HIV-1 infection. J NeuroAIDS. 2004; 2:33-43. [PubMed: 16873204]

Kumar R, Orsoni S, Norman L, Verma AS, Tirado G, Giavedoni LD, Staprans S, Miller GM, Buch SJ, Kumar A. Chronic morphine exposure causes pronounced virus replication in cerebral compartment and accelerated onset of AIDS in SIV/SHIV-infected Indian rhesus macaques. Virology. 2006; 354:192-206. [PubMed: 16876224]

Lee EO, Kim SE, Park HK, Kang JL, Chong YH. Extracellular HIV-1 Tat upregulates TNF-alpha dependent MCP-1/CCL2 production via activation of ERK1/2 pathway in rat hippocampal slice cultures: inhibition by resveratrol, a polyphenolic phytostilbene. Exp Neurol. 2011; 229:399-408. [PubMed: 21419119]

Li ZCN, Shan L, Gong S, Yin Q, Jiang X. Inducible Expression of Functional Mu Opioid Receptors in Murine Dendritic Cells. Journal of Neuroimmune Pharmacology. 2009; 4:359. [PubMed: 19189219]

Messmer DHI, Hitosugi N, Schmidt-Wolf IGH, Singhal PC. Morphine Reciprocally Regulates IL-10 and IL-12 Production by Monocyte-Derived Human Dendritic Cells and Enhances T Cell Activation. Molecular Medicine. 2006; 12:284-290. [PubMed: 17380193]

Noel RJ Jr. Kumar A. Virus replication and disease progression inversely correlate with SIV tat evolution in morphine-dependent and SIV/SHIV-infected Indian rhesus macaques. Virology. 2006; 346:127-38. [PubMed: 16313937]

O’Brien M, Manches O, Sabado RL, Baranda SJ, Wang Y, Marie I, Rolnitzky L, Markowitz M, Margolis DM, Levy D, Bhardwaj N. Spatiotemporal trafficking of HIV in human plasmacytoid 
dendritic cells defines a persistently IFN-alpha-producing and partially matured phenotype. J Clin Invest. 2011; 121:1088-101. [PubMed: 21339641]

Orenstein JM, Fox C, Wahl SM. Macrophages as a source of HIV during opportunistic infections. Science. 1997; 276:1857-61. [PubMed: 9188531]

Perez-Casanova A, Husain K, Noel RJ Jr. Rivera-Amill V, Kumar A. Interaction of SIV/SHIV infection and morphine on plasma oxidant/antioxidant balance in macaque. Mol Cell Biochem. 2008; 308:169-75. [PubMed: 17934700]

Perez-Casanova A, Noel RJ Jr. Rivera-Amill V, Husain K, Kumar A. Morphine-mediated deterioration of oxidative stress leads to rapid disease progression in SIV/SHIV-infected macaques. AIDS Res Hum Retroviruses. 2007; 23:1004-7. [PubMed: 17725417]

Pichyangkul S, Saengkrai P, Yongvanitchit K, Limsomwong C, Gettayacamin M, Walsh DS, Stewart VA, Ballou WR, Heppner DG. Isolation and characterization of rhesus blood dendritic cells using flow cytometry. J Immunol Methods. 2001; 252:15-23. [PubMed: 11334961]

Potula R, Dhillion N, Sui Y, Zien CA, Funa K, Pinson D, Mayo MS, Singh DK, Narayan O, Buch S. Association of platelet-derived growth factor-B chain with simian human immunodeficiency virus encephalitis. Am J Pathol. 2004; 165:815-24. [PubMed: 15331406]

Raghavan R, Cheney PD, Raymond LA, Joag SV, Stephens EB, Adany I, Pinson DM, Li Z, Marcario JK, Jia F, Wang C, Foresman L, Berman NE, Narayan O. Morphological correlates of neurological dysfunction in macaques infected with neurovirulent simian immunodeficiency virus. Neuropathol Appl Neurobiol. 1999; 25:285-94. [PubMed: 10476045]

Sabado RL, O’Brien M, Subedi A, Qin L, Hu N, Taylor E, Dibben O, Stacey A, Fellay J, Shianna KV, Siegal F, Shodell M, Shah K, Larsson M, Lifson J, Nadas A, Marmor M, Hutt R, Margolis D, Garmon D, Markowitz M, Valentine F, Borrow P, Bhardwaj N. Evidence of dysregulation of dendritic cells in primary HIV infection. Blood. 2010; 116:3839-52. [PubMed: 20693428]

Sagar D, Lamontagne A, Foss CA, Khan ZK, Pomper MG, Jain P. Dendritic cell CNS recruitment correlates with disease severity in EAE via CCL2 chemotaxis at the blood-brain barrier through paracellular transmigration and ERK activation. J Neuroinflammation. 2012; 9:245. [PubMed: 23102113]

Shapshak P, Kangueane P, Fujimura RK, Commins D, Chiappelli F, Singer E, Levine AJ, Minagar A, Novembre FJ, Somboonwit C, Nath A, Sinnott JT. Editorial neuroAIDS review. AIDS. 2011; 25:123-41. [PubMed: 21076277]

Soilleux EJ, Morris LS, Leslie G, Chehimi J, Luo Q, Levroney E, Trowsdale J, Montaner LJ, Doms RW, Weissman D, Coleman N, Lee B. Constitutive and induced expression of DC-SIGN on dendritic cell and macrophage subpopulations in situ and in vitro. J Leukoc Biol. 2002; 71:445-57. [PubMed: 11867682]

Spudich S, Gisslen M, Hagberg L, Lee E, Liegler T, Brew B, Fuchs D, Tambussi G, Cinque P, Hecht FM, Price RW. Central nervous system immune activation characterizes primary human immunodeficiency virus 1 infection even in participants with minimal cerebrospinal fluid viral burden. J Infect Dis. 2011; 204:753-60. [PubMed: 21844301]

Suzuki S, Chuang AJ, Chuang LF, Doi RH, Chuang RY. Morphine promotes simian acquired immunodeficiency syndrome virus replication in monkey peripheral mononuclear cells: induction of CC chemokine receptor 5 expression for virus entry. J Infect Dis. 2002; 185:1826-9. [PubMed: 12085334]

Tirado G, Kumar A. Evolution of SIV envelope in morphine-dependent rhesus macaques with rapid disease progression. AIDS Res Hum Retroviruses. 2006; 22:114-9. [PubMed: 16438654]

Wen H, Lu Y, Yao H, Buch S. Morphine induces expression of platelet-derived growth factor in human brain microvascular endothelial cells: implication for vascular permeability. PLoS One. 2011; 6:e21707. [PubMed: 21738771]

Xia H, Liu H, Zhang G, Zheng Y. Phenotype and function of monocyte-derived dendritic cells from chinese rhesus macaques. Cell Mol Immunol. 2009; 6:159-65. [PubMed: 19567198]

Yu Kimata MT, Cella M, Biggins JE, Rorex C, White R, Hicks S, Wilson JM, Patel PG, Allan JS, Colonna M, Kimata JT. Capture and transfer of simian immunodeficiency virus by macaque dendritic cells is enhanced by DC-SIGN. J Virol. 2002; 76:11827-36. [PubMed: 12414925] 
Zhou LJ, Tedder TF. Human blood dendritic cells selectively express CD83, a member of the immunoglobulin superfamily. J Immunol. 1995; 154:3821-35. [PubMed: 7706722]

Zink MC, Brice AK, Kelly KM, Queen SE, Gama L, Li M, Adams RJ, Bartizal C, Varrone J, Rabi SA, Graham DR, Tarwater PM, Mankowski JL, Clements JE. Simian immunodeficiency virus-infected macaques treated with highly active antiretroviral therapy have reduced central nervous system viral replication and inflammation but persistence of viral DNA. J Infect Dis. 2010; 202:161-70. [PubMed: 20497048]

Zink MC, Coleman GD, Mankowski JL, Adams RJ, Tarwater PM, Fox K, Clements JE. Increased macrophage chemoattractant protein-1 in cerebrospinal fluid precedes and predicts simian immunodeficiency virus encephalitis. J Infect Dis. 2001; 184:1015-21. [PubMed: 11574916]

Zozulya AL, Ortler S, Lee J, Weidenfeller C, Sandor M, Wiendl H, Fabry Z. Intracerebral dendritic cells critically modulate encephalitogenic versus regulatory immune responses in the CNS. J Neurosci. 2009; 29:140-52. [PubMed: 19129392] 

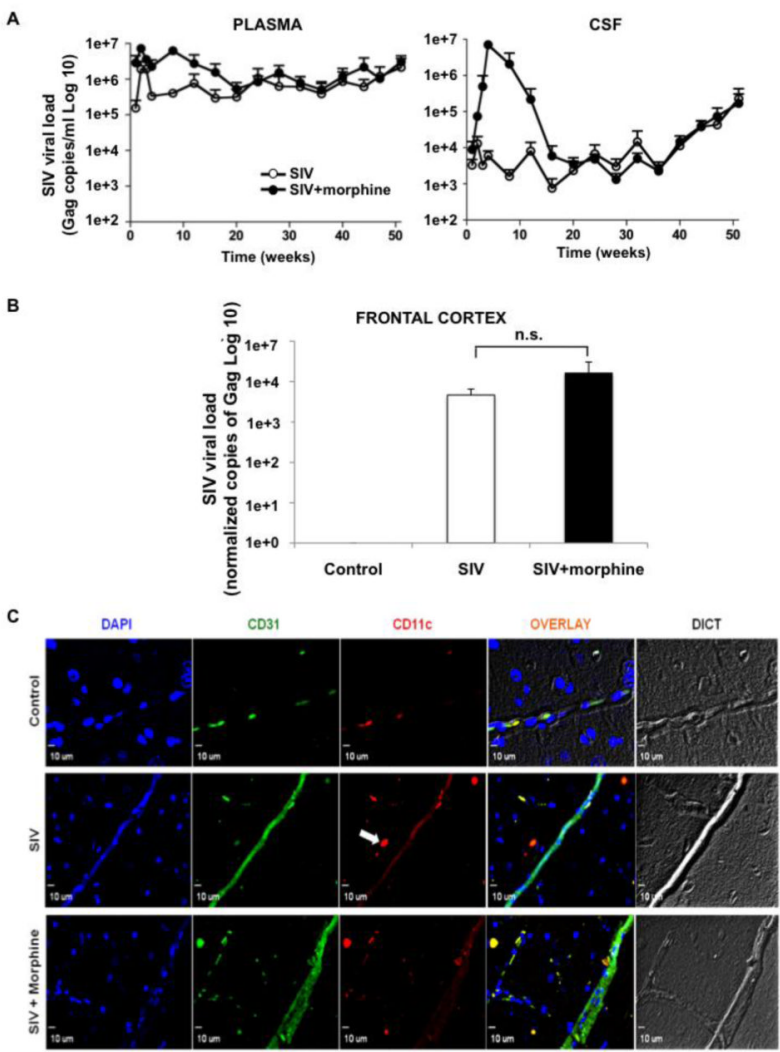

Figure 1. CD11c ${ }^{+}$cells in brain parenchyma of SIV-infected rhesus macaques with high viral burden

(A) Average viral load (Gag copies/ml) over a period of 1-51 weeks post viral inoculation in plasma (top, left panel) and CSF (top, right panel) in SIV-infected monkeys treated with morphine compared to those without morphine. (B) Frontal cortex tissue specific viral RNA titer (Gag copies/million GAPDH copies) of control and SIV-infected macaques with or without morphine. Average viral loads and calculated standard error bars are presented from three macaques per group. (C) After IHC-P staining, individual blood vessels in the frontal cortex were identified by CD31 staining (green). The control group shows a mostly contained $\mathrm{CD} 11 \mathrm{c}^{+}$population (red) within the microvasculature, whereas the SIV-infected and SIV + morphine animals demonstrate CD11 $\mathrm{c}^{+}$cell presence (white arrow) in the brain parenchyma. Representative images at 40X magnification are shown. 


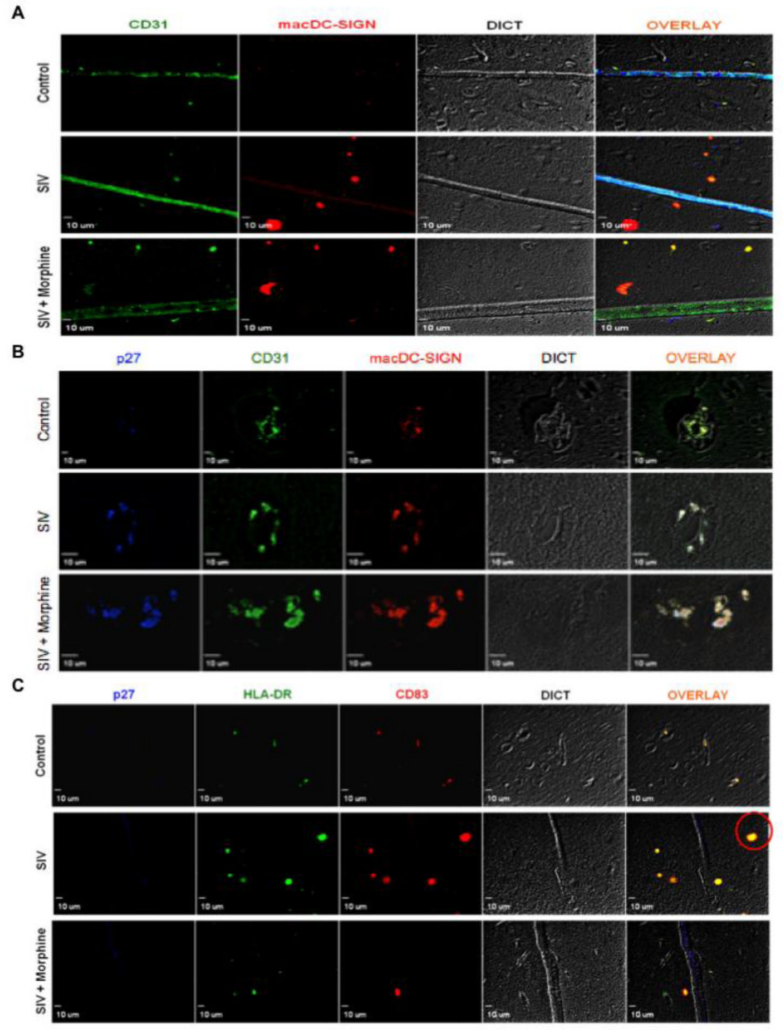

Figure 2. Dendritic cell infiltration into the CNS during SIV infection

(A) After IHC-P staining, individual blood vessels in the frontal cortex were identified by CD31 staining (green) and macaque DC-SIGN staining (red) identified dendritic cells. The control group does not exhibit macDC-SIGN ${ }^{+}$cells, however in SIV infection DCs are shown to transmigrate into the brain parenchyma. (B) Perivascular cuffing of dendritic cells is observed in SIV and SIV + morphine macaques at the site of SIV lesions as determined by staining with CD31 (green), macDC-SIGN (red) and SIV p27 (blue). Control animals do not show perivascular accumulation of lymphocytes. (C) Dendritic cells with a mature phenotype are observed in SIV and SIV + morphine animals, compared to control animals, as demonstrated by staining with HLA-DR (green) and CD83 (red) (red circle). Representative images at 40X magnification are shown. 
Table 1

Enumeration of $\mathrm{CD} 11 \mathrm{c}^{+}$cells in brain parenchyma of macaques.

\begin{tabular}{|c|c|c|c|}
\hline Animal & $\begin{array}{c}\text { Average } \\
\text { Nuclei }^{*}\end{array}$ & CD11c $^{+}$cells & $\begin{array}{c}\text { Frequency } \\
\pm \text { SEM }\end{array}$ \\
\hline Control & 102 & 1 & $1.0 \% \pm 1.0$ \\
\hline SIV & 205 & 8 & $3.9 \% \pm 0.2$ \\
\hline SIV + Morphine & 165 & 10 & $6.2 \% \pm 1.8$ \\
\hline
\end{tabular}

Cells were counterstained with DAPI and various fields of vision were quantified to determine the frequency of CD11c ${ }^{+}$cells out of the total population within each group. 